\title{
Effects of light intensities and photoperiods on growth and proteolytic activity in purple non-sulfur marine bacterium, Afifella marina strain ME (KC205142)
}

\author{
Sujjat Al-Azad*, Tan Kar Soon, Julian Ransangan \\ Borneo Marine Research Institute, University Malaysia Sabah, Kota Kinabalu, Malaysia \\ Email: sujjat@ums.edu.my
}

Received 1 July 2013; revised 1 August 2013; accepted 2 September 2013

Copyright (C) 2013 Sujjat Al-Azad et al. This is an open access article distributed under the Creative Commons Attribution License, which permits unrestricted use, distribution, and reproduction in any medium, provided the original work is properly cited.

\begin{abstract}
Afifella marina strain ME (KC205142), a purple nonsulfur bacterium was isolated from mangrove habitats of Sabah. The effects of light intensities and photoperiods on proteolytic activity in Afifella marina strain ME (KC205142) were investigated. Secretion of proteolytic enzymes in Afifella marina was preliminarily assessed by skim milk agarose media. Subsequently, light intensities, such as, dark, 1000, 1500, 2000, 2500, 3000, 3500, 4000, 4500 and 5000 lux were used to evaluate the effects on proteolytic activity in Afifella marina strain ME under anaerobic condition. After that, the effect of photoperiods on proteolytic activity was monitored under anaerobic light condition (3000 lux) at $0 \mathrm{~h}(0 \mathrm{~L} / 24 \mathrm{D}), 6 \mathrm{~h}(6 \mathrm{~L} / 18 \mathrm{D}), 12 \mathrm{~h}$ (12L/12D), $18 \mathrm{~h} \mathrm{(18L/6D)}$ and $24 \mathrm{~h}(24 \mathrm{~L} / 0 \mathrm{D})$ of photoperiod. The highest proteolytic activity of $74.67 \mathrm{U}$ was recorded at 3000 lux illumination light intensity. The proteolytic activity in bacterium Afifella marina strain ME was positively associated with the dry cell weight. The proteolytic activity of $72.67 \mathrm{U}$ in bacterium Afifella marina strain $\mathrm{ME}$ at $18 \mathrm{~h}(18 \mathrm{~L} / 6 \mathrm{D})$ photoperiod is not significantly different $(p>0.05)$ from proteolytic activity of $74.67 \mathrm{U}$ recorded at continuous light (24L/0D) condition. Light intensity of 3000 lux, culture period of $48 \mathrm{~h}$ and a photoperiod of $18 \mathrm{~h}(18 \mathrm{~L} /$ 6D) were the optimum parameters for proteolytic activity in bacterium Afifella marina strain ME.
\end{abstract}

Keywords: Afifella marina; Light Intensity; Photoperiod; Proteolytic Activity; Purple Non-Sulfur Bacteria

${ }^{*}$ Corresponding author.

\section{INTRODUCTION}

Purple non-sulfur bacteria (PNSB) are anoxygenic photosynthetic bacteria that prefer to live as photoheterotrophs. These groups of bacteria also inhabit in a wide range of natural environments such as sediments [1], coastal seawaters [2], brackish water [3], mud from the bottom of tidal pool [3] and lakes [4]. PNSB has been applied in bioremediation of sardine waste water [5], aquaculture feed additive to enhance growth and survival of post larvae of tiger shrimp [6], production of bio-fuel [7], production of antiviral substances [8], production of enzymes [9], bioremediation of heavy metal from polluted water [10] and production of single cell protein [11].

PNSB are also known to produce extracellular enzymes such as proteases, lipases, esterase and alkaline phosphatase [12]. Proteases are well known enzymes for their wide range of application in food industries, detergent industries, pharmaceutical industries and aquaculture industries. Purple non-sulfur bacterium, Rubrivivax gelatinosus grown in GM media under anaerobic light condition for $48 \mathrm{~h}$ has been reported to produce significant level of proteolytic activity [13]. Extracellular proteases within the bacterium extracellular polymeric substances matrix play an important role in providing nutrients, and alter extracellular polymeric substances composition as they respond to different environmental conditions. The extracellular enzymes contributed to the nutrition of the bacterium by hydrolyzing large molecular organic compounds to smaller oligomers and monomeric components which can directly be absorbed by the cells [14].

Studies concluded that culture substrates, $\mathrm{pH}$ and temperature are the major factors that influence the bacterium proteolytic activities. PNSB can photoassimilate a 
wide variety of organic compounds such as acetate, pyruvate, dicarboxylic acids, fatty acids and sugar [15]. However, high level of complex organic polymers induces the proteolytic activities, while simple compounds inhibit the bacterium proteolytic activities [16]. Low temperature always results in slow biological activity while high temperature around $40^{\circ} \mathrm{C}$ has been reported to inhibit the growth of PNSB [17]. A temperature of $30^{\circ} \mathrm{C}$ was reported to be the optimum temperature for protelytic activities in bacteria such as Bacillus sp. [18]. The maximal protease production was reported in basal medium, where $\mathrm{pH} 8$ was documented to be the optimum $\mathrm{pH}$ value for proteolytic activity in Bacillus sp. [19].

Light intensity is an important factor that controls the growth of PNSB. The optimum light intensity for the growth of PNSB is in the range of 2500 lux to 3000 lux. The highest dry cell weight of $5.6 \mathrm{~g} / 1$ of Rhodocyclus gelatinosus is obtained when cultured in glutamatemalate (GMM) media at 3000 lux of illumination light intensity [17]. Azad et al. [6] recorded the highest dry cell weight of $4.8 \mathrm{~g} / 1$ in Rhodovulum sulfidopilum that was grown in GMM media under anaerobic condition at 2500 lux light intensity and a temperature of $30^{\circ} \mathrm{C} \pm 2^{\circ} \mathrm{C}$. Protease production in Rubrivivax gelatinosus was reported to be light inducible, therefore, it is likely that the light intensity also influences the proteolytic activity in PNSB. However, limited information is known about the effects of light intensities and photoperiods on the proteolytic activities in PNSB. Therefore, the objectives of this study were to assess the effects of light intensities and photoperiods on the proteolytic activities in Afifella marina strain ME.

\section{MATERIALS AND METHODS}

\subsection{Bacterium and Culture}

Afifella marina, strain ME (KC205142) was obtained from the culture collection of Borneo Marine Research Institute, University Malaysia Sabah, Malaysia. This strain was isolated from exposed mangrove mud sample of KingFisher, Sabah, Malaysia. A single colony of Afifella marina strain ME was inoculated in Mc. Corney bottle containing $25 \mathrm{ml}$ of 112 media and incubated anaerobically under 2500 lux illumination light intensity at a temperature of $30^{\circ} \mathrm{C} \pm 2^{\circ} \mathrm{C}$ for 7 days. The composition of 112 media (g/l) was: $10.0 \mathrm{~g}$ of yeast-extract, $0.5 \mathrm{~g}$ of magnesium sulphate, $30 \mathrm{~g}$ of sodium chloride and $1.0 \mathrm{~g}$ of dipotassium hydrogen phosphate.

\subsection{Inoculum Preparation}

One milliliter of the best grown culture was taken from previously culture bottle and transferred into a new Mc. Corney bottle containing $24 \mathrm{ml}$ of freshly prepared sterile 112 media. The bottles were then incubated the same way as stated previously. A $48 \mathrm{~h}$ culture was used as the inoculum in subsequent experiments.

\subsection{Preliminary Test for Proteolytic Activity in Afifella marina Strain ME}

Afifella marina strain ME was tested for the production of proteolytic enzyme by incubating the cells on solidified 112 media supplemented with $10 \%$ skim milk. A 48 $\mathrm{h}$ culture plate was opened and observed the present of clear zone around the bacteria colony.

\subsection{Proteolytic Activity Characterization}

A $48 \mathrm{~h}$ inoculum with $10 \%(\mathrm{v} / \mathrm{v})$ was inoculated into triplicate bottles containing sterilised 112 media and incubated anaerobically at a temperature of $30^{\circ} \mathrm{C} \pm 2^{\circ} \mathrm{C}$ under 2500 lux of light intensity for $120 \mathrm{~h}$. Three bottles from each level of light intensity were selected randomly after $0 \mathrm{~h}, 24 \mathrm{~h}, 48 \mathrm{~h}, 96 \mathrm{~h}$, and 120 hours of incubation to analyse the dry cell weight $(\mathrm{g} / \mathrm{l})$ and proteolytic activity (U). After 0 h, 24 h, 48 h, 72 h, $96 \mathrm{~h}$ and 120 h, three bottles of culture were taken randomly for analysis of the dry cell weight $(\mathrm{g} / \mathrm{l})$ and proteolytic activity (U).

\subsection{Proteolytic Activity in Afifella marina Strain ME with Levels of Light Intensities}

Proteolytic activities in bacterium Afifella marina strain ME was monitored with various light intensities. Triplicate bottles of 112 media were inoculated with $10 \%(\mathrm{v} / \mathrm{v})$ $48 \mathrm{~h}$ inoculum and incubated anaerobically at $30^{\circ} \mathrm{C} \pm 2^{\circ} \mathrm{C}$ under dark, 1000, 1500, 2000, 2500 (control), 3000, $3500,4000,4500$ and 5000 lux illumination of light intensities.

\subsection{Proteolytic Activity in Afifella marina Strain ME with Levels of Photoperiod}

Triplicate bottles of 112 media were inoculated with $10 \%(\mathrm{v} / \mathrm{v}) 48 \mathrm{~h}$ of inoculum and incubated anaerobically at $30^{\circ} \mathrm{C} \pm 2^{\circ} \mathrm{C}$ with 3000 lux light intensity under photoperiods of $0 \mathrm{~h}$ light $(0 \mathrm{~L} / 24 \mathrm{D}), 6 \mathrm{~h}$ light $(6 \mathrm{~L} / 18 \mathrm{D}), 12 \mathrm{~h}$ light (12L/12D), $18 \mathrm{~h}$ light (18L/6D) and $24 \mathrm{~h}$ light (24L/0D). The light intensity of 3000 lux was selected base on previous experiment, which showed the highest proteolytic activity in Afifella marina strain ME. The dry cell weight (g/l) and proteolytic activity (U) of Afifella marina strain ME after 0 h, 24 h, 48 h, 96 h, and $120 \mathrm{~h}$ of incubation were analysed.

\subsection{Analytical Parameters}

Dry Cell Weight

The bacterium cells were collected by centrifuging $10 \mathrm{ml}$ of culture at $4400 \mathrm{rpm}$ for 20 minutes at $4^{\circ} \mathrm{C}$. The process was repeated 3 times, after washing and re-suspended 
the cells in distilled water. Subsequently, the dry cell weight is obtained by drying the cell pallet in oven at a temperature of $105^{\circ} \mathrm{C}$ until constant weight achieved. The dry cell weight was calculated as the formula given by Sawada et al. [20]:

$$
\begin{aligned}
& \text { Dry cell weight }(\mathrm{g} / \mathrm{l}) \\
& =\frac{(\text { Final weight }- \text { Initial weight })}{\mathrm{v}} \times 1000
\end{aligned}
$$

where:

Initial weight $=$ plastic centrifuge tube weight $(\mathrm{g})$

Final weight $=$ plastic centrifuge tube weight $(g)+$ dry cell weight $(\mathrm{g})$

$$
\mathrm{v}=\text { Volume of sample }(\mathrm{ml})
$$

\subsection{Proteolytic Activity}

Proteolytic activity in bacterium Afifella marina strain ME was assayed using azocasein as substrates according to method described by Winkler and Stuckman [21]. In this assay, digestion of azoproteins with proteolytic enzymes at $38^{\circ} \mathrm{C}$ results in the formation of coloured components soluble in trichloroacetic acid. This coloured compound has maximum absorption at a wavelength of $440 \mathrm{~nm}$. The proteolytic activity is expressed as enzymatic unit (U), where one unit of proteolytic activity is defined as the amount of enzyme that produces an increase in absorbance of 0.01 under assay conditions. The absorbance was measured using 100 VIS spectrophotometer (Busk Scientific, USA).

\subsection{Statistical Analysis}

Statistical analyses were performed using the SPSS Windows Statistical Package (version 19.0). Tests were judged with significant at $\mathrm{p}<0.05$ level. All variables were tested for normality and homogeneity of variances. Data which satisfy the assumptions of normality and homogeneity, parametric tests (one-way ANOVA, Independent t-test, and Pearson correlation test) were performed.

\section{RESULTS AND DISCUSSION}

\subsection{Proteolytic Enzymes Production in Afifella marina Strain ME}

A clear zone was observed when Afifella marina strain ME was grown on skim milk plate under anaerobic light condition for $48 \mathrm{~h}$ (Figure 1). Similar observations were reported in other studies where purple non-sulfur bacteria such as Rhodopseudomonas palustris grown in Malate basal medium at $28^{\circ} \mathrm{C}$ [22] and Rubrivivax gelatinosus KDDS1 grown in Glutamate-malate (GM) medium under anaerobic light conditions at light intensity of 3000 lux and a temperature of $35^{\circ} \mathrm{C}$ for $48 \mathrm{~h}$ [13] exhibited proteolytic activity. The result of this study shows that Afifella marina strain ME do secrete of extracellular protease under anaerobic light conditions.

\subsection{Growth and Proteolytic Activity Profile of Afifella marina Strain ME}

Afifella marina strain ME incubated under anaerobic light condition at light intensity of 2500 lux and at a temperature of $30^{\circ} \mathrm{C}$ had shown a sigmoid growth curve. The growth began with a negligible lag phase, followed by an exponential phase until $72 \mathrm{~h}$ of incubation then entered a deceleration phase until $120 \mathrm{~h}$ of incubation (Figure 2). The highest dry cell weight of $4.34 \mathrm{~g} / 1$ was achieved at $72 \mathrm{~h}$ culture. The optimum culturing period was similar to other studies. Rhodomicrobium vannielii grown in GM media produced the highest dry cell weight of $1.1 \mathrm{~g} / 1$ at $72 \mathrm{~h}$ culture under anaerobic light condition (2000 lux) [23]. Rhodovulum sulfidophilum grown in sardine processing effluence recorded highest dry cell weight of 2.8 $\mathrm{g} / 1$ at $72 \mathrm{~h}$ culture under anaerobic light condition (2500

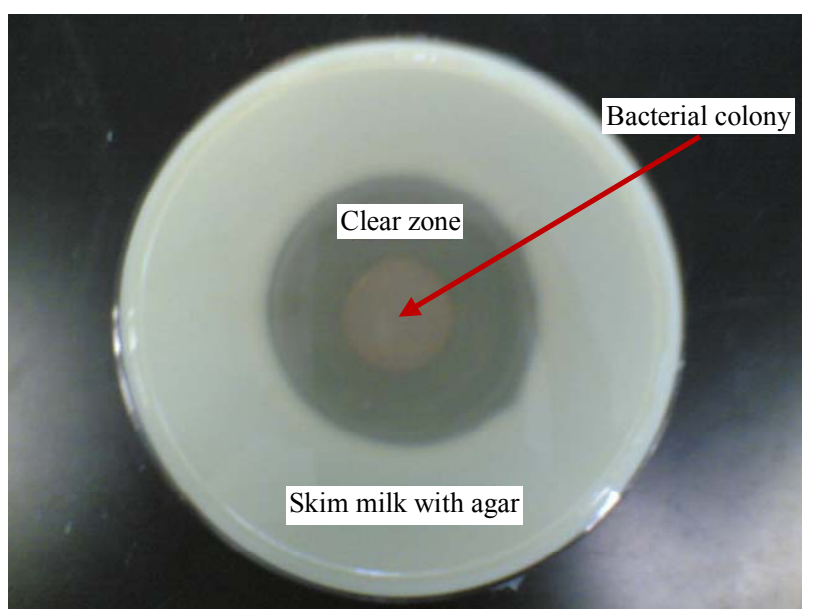

Figure 1. Zone clearance by Afifella marina strain ME grown on skim milk plate under anaerobic light condition (2500 lux) and at a temperature of $30^{\circ} \mathrm{C} \pm 2{ }^{\circ} \mathrm{C}$ for $48 \mathrm{~h}$.

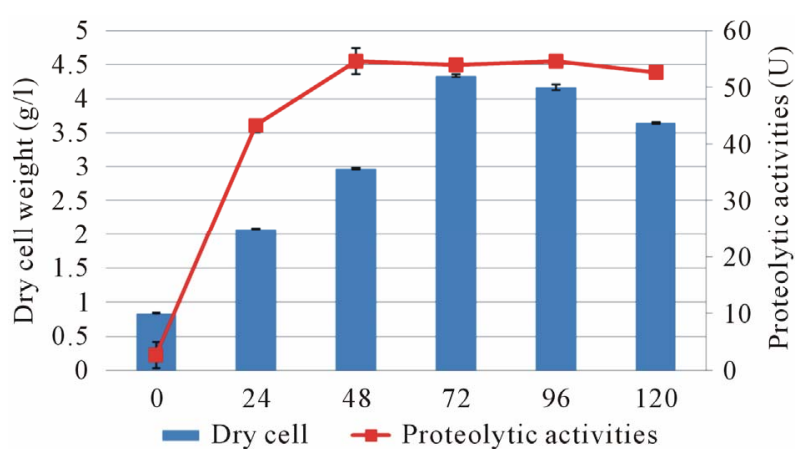

Figure 2. Dry cell weight (g/l) and proteolytic activities (U) of Afifella marina strain ME in 112 media incubated under anaerobic light condition ( $2.5 \mathrm{k}$ lux illumination, control) for the period of 120 hours at a temperature of $30^{\circ} \mathrm{C} \pm 2^{\circ} \mathrm{C}$. 
lux) [5]. The decrease in dry cell weight after $72 \mathrm{~h}$ was believed to be due to the cells had entered stationary phase or were dead [23]. This suggested the optimum dry cell weight production of Afifella marina strain $\mathrm{ME}$ is at $72 \mathrm{~h}$ culture.

Interestingly, the proteolytic activity corresponding with growth where the proteolytic activity of Afifella marina strain ME was increased drastically to $54.67 \mathrm{U}$ within $48 \mathrm{~h}$ of incubation. Subsequently, the level proteolytic activity of Afifella marina remains constant at 54.7 $\mathrm{U}$ until $120 \mathrm{~h}$ of incubation. The maximum proteolytic activity of $54.7 \mathrm{U}$ was recorded at $48 \mathrm{~h}$ of incubation in this study. The optimum incubation time of $48 \mathrm{~h}$ recorded in Afifella marina strain ME was in agreement with Shivanand and Jayaraman [24], where $48 \mathrm{~h}$ incubation was the optimum incubation time for Bacillus aquimaris strain VITP4 too. Bacteria were reported to synthesis extracellular enzymes actively within $24 \mathrm{~h}$ of incubation. However, the quantitative enzymes activities might increase until $72 \mathrm{~h}$ of incubation [18]. This study shows that the proteolytic activities of Afifella marina strain ME optimum at $48 \mathrm{~h}$ culture.

The maximum proteolytic activity of $57.4 \mathrm{U}$ at $48 \mathrm{~h}$ culture in Afifella marina strain ME was doubled the proteolytic activities (25 U) of Rubrivivax gelatinosus that was grown in GM media under anaerobic light condition (3000 lux) at a temperature of $35^{\circ} \mathrm{C}$ [13]. This suggests that Afifella marina strain ME is a good proteolytic enzymes producer among PNSB. Compared to other microbial proteolytic producers, the proteolytic activity in Afifella marina strain ME, the purple nonsulfur bacteria was much lower than that the proteolytic activity (350 to $410 \mathrm{U}$ ) in Bacillus sp. [25]. Maximum proteolytic activity of Bacillus aquimaris strain VITP4 of $630 \mathrm{U} / \mathrm{ml}$ was recorded when cultured in zobell broth at $37^{\circ} \mathrm{C}$ for $48 \mathrm{~h}$ of incubation [24]. It is not surprising because Bacillus spp. is a well known proteolytic enzymes producer. It is reasonable to believe that higher proteolytic activity in Bacillus aquimaris strain VITP4 than Afifella marina strain ME is due to Bacillus spp. are naturally biosynthesis higher level of proteolytic enzymes than PNSB. However, the proteolytic avtivities in Afifella marina strain ME (57.4 U) is comparable to proteolytic activity in probiotic bacteria strain TP3B that isolated from tilapia $(51.0 \mathrm{U})$ [26]. This indicates the Afifella marina strain ME could be a potential probiotic bacteria.

\subsection{Effect of Light Intensities on Dry Cell Weight and Proteolytic Activity in Afifella marina Strain ME}

Dry cell weight and proteolytic activity of Afifella marina strain ME were strongly affected by light intensity. Increase in light intensities from dark to 3000 lux was associated with increase in dry cell weight from 1.28 to $4.97 \mathrm{~g} / \mathrm{l}$ and proteolytic activity from $16.67 \pm 2.31 \mathrm{U}$ to $74.67 \pm 2.31 \mathrm{U}$ (Figure 3). This observation was comparable to other study where the proteolytic activity of Bacillus aquimaris strain VITP4 grown in zobell broth at $37^{\circ} \mathrm{C}$ also nearly corresponded with the growth and it was maximal at stationary phase [24].

The maximum dry cell weight of $4.97 \mathrm{~g} / 1$ and proteolytic activity of $74.67 \pm 2.31 \mathrm{U}$ in Afifella marina strain ME were recorded at 3000 lux intensity in Afifella marina strain $\mathrm{ME}$ under anaerobic conditions at $48 \mathrm{~h}$ culture. These values were significantly higher $(p<0.05)$ than that the dry cell weight and proteolytic activities recorded at other light intensities. Rhodocyclus gelatinosus grown in GM media also yield the maximum dry cell weight of $5.6 \mathrm{~g} / \mathrm{l}$ under anaerobic light condition at light intensity of 3000 lux and a temperature of $30^{\circ} \mathrm{C} \pm 2^{\circ} \mathrm{C}$ [17]. PNSB prefers to grow as photoheterotrophs in the presence of light and dissolved organic matter [3]. Therefore, increase in dry cell weight is associated with increase in light intensity. On the other hand, proteolytic activity in purple non-sulfur bacterium, Rubrivivax gelatinosus was reported to be light inducible and light dependent [13]. The light inducible proteinase complex is associated with thylakoid membranes. The light inducible serine type proteinase is released under light stress condition [27]. So, higher proteolytic activity of Afifella marina strain ME in higher light intensity suggests that it may be also light dependent.

However, the dry cell weight and proteolytic activity were then decreased to $3.2 \mathrm{~g} / 1$ and $50.00 \pm 2.00 \mathrm{U}$, respectively at 4000 lux of light intensity. Rhodomicrobium bvanielii grown in GM media under anaerobic light condition at 4000 lux also results in low growth of $1.1 \mathrm{~g} / \mathrm{l}$ [23]. This simply indicates that high light intensity of $\geq 4000$ lux inhibit the growth of cell due to the heat generated in the medium. The lower the proteolytic activity at high light intensity of $\geq 4000$ lux can be explained by the low dry cell weight. The cells were

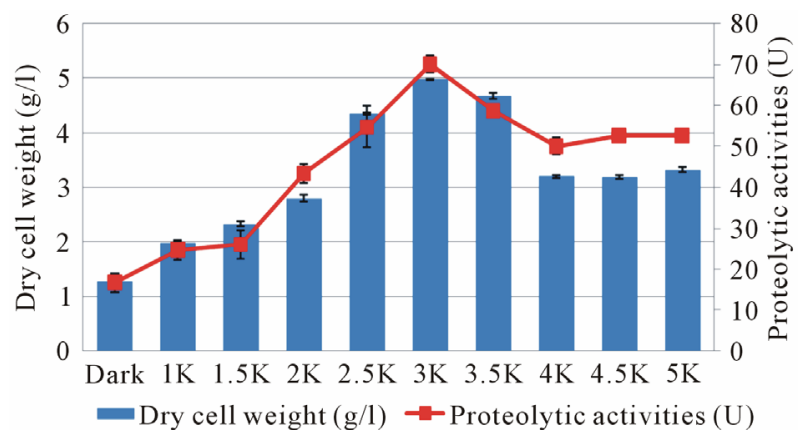

Figure 3. Effect of light intensities on maximum dry cell weight $(\mathrm{g} / \mathrm{l})$ and proteolytic activities (U) in Afifella marina strain ME in 112 media incubated under anaerobic light conditions at a temperature of $30^{\circ} \mathrm{C} \pm 2^{\circ} \mathrm{C}$. 
dead due to high temperature in the culture then resulting in proteolytic activity also decreased.

This study showed a strong positive correlation $(\mathrm{R}=$ $0.839, \mathrm{p}<0.01$ ) between proteolytic activity and yield in dry cell weight. One of the functions of extracellular enzymes in heterotrophic microorganisms is contributed to the nutrition by hydrolyzing large molecular organic compounds before being absorbed by cells [14]. The higher proteolytic activity at higher dry cell weight suggests that Afifella marina might secrete proteolytic enzyme to hydrolyze high molecular weight compound outside the cell, prior to the uptake of growth. However, further studies are essential to validate this assumption.

\subsection{Effect of Photoperiod on Dry Cell Weight and Extracellular Proteolytic Activity in Afifella marina Strain ME}

Dry cell weight and proteolytic activity in Afifella marina strain ME was influenced by photoperiod where increase in photoperiod associated with increase in proteolytic activity (Figure 4). The highest dry cell weight of 4.97 $\mathrm{g} / \mathrm{l}$ and proteolytic activity of $74.7 \pm 2.31 \mathrm{U}$ were recorded at continuous light condition $(24 \mathrm{~L} / 0 \mathrm{D})$. These values were significantly higher $(p<0.05)$ than that dry cell weight and proteolytic activity at dark (0L/24D), $6 \mathrm{~h}$ light $(6 \mathrm{~L} / 18 \mathrm{D})$ and $12 \mathrm{~h}$ light $(12 \mathrm{~L} / 12 \mathrm{D})$. It is not surprising because continuous light condition favours the growth of photosynthetic bacterial cells [28].

However, there was no significance difference $(p>$ $0.05)$ in dry cell weight and proteolytic activity between continuous light condition $(24 \mathrm{~L} / 0 \mathrm{D})(74.7 \pm 2.31 \mathrm{U})$ and $18 \mathrm{~h}(18 \mathrm{~L} / 6 \mathrm{D})$ light condition $(72.7 \pm 4.6 \mathrm{U})$. This indicates that reducing in photoperiod still works without significantly reducing the growth and production of metabolites is possible. Eroglu et al. [29] reported Rhodobacter sphaeroides grown in olive mill wastewater under anaerobic light condition $\left(200 \mathrm{~W} / \mathrm{m}^{2}\right)$ at a temperature of $32^{\circ} \mathrm{C}$ showed no significant difference in dry cell weight

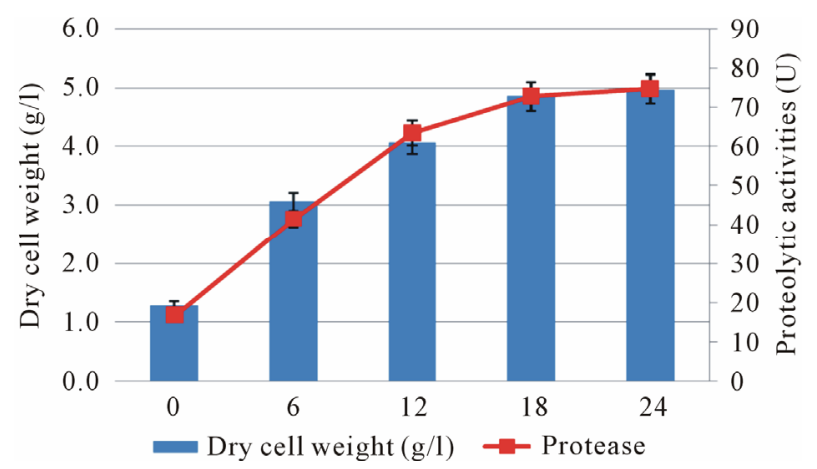

Figure 4. Effect of photoperiod on proteolytic activities (U) in Afifella marina strain ME in 112 media incubated under anaerobic light condition (3000 lux) at $48 \mathrm{~h}$ culture and a temperature of $30^{\circ} \mathrm{C} \pm 2{ }^{\circ} \mathrm{C}$. between $12 \mathrm{~h}$ light $(12 \mathrm{~L} / 12 \mathrm{D})$ of $0.5 \mathrm{~g} / \mathrm{l}$ and continuous light condition (24L/0D) of $0.55 \mathrm{~g} / \mathrm{l}$. Moreover, Liqin et al. [30] also reported $18 \mathrm{~h}$ photoperiod $(18 \mathrm{~L} / 6 \mathrm{D})$ was the optimum photoperiods for extracellular polymeric substances $(105 \mathrm{~g} / \mathrm{l})$ produced by photosynthetic bacteria at a temperature of $30^{\circ} \mathrm{C}$ and light intensity of $80 \mu \mathrm{E} / \mathrm{m}^{2} \mathrm{~s}$. Thus, present study suggests that the continuous light culture condition (24L/0D) can be replaced by $18 \mathrm{~h}$ of photoperiods $(18 \mathrm{~L} / 6 \mathrm{D})$ to yield the similar proteolytic activity in Afifella marina strain ME.

\section{CONCLUSION}

Afifella marina strain ME (KC205142) produces protease under anaerobic light conditions at temperature of $30^{\circ} \mathrm{C} \pm 2^{\circ} \mathrm{C}$. The proteolytic activity was positively correlated with the dry cell weight. Optimum proteolytic activity was recorded at $48 \mathrm{~h}$ of incubation. The optimum light intensity and photoperiods of proteolytic activity in Afifella marina strain ME are at 3000 lux and $18 \mathrm{~h}(18 \mathrm{~L} /$ 6D) light, respectively.

\section{ACKNOWLEDGEMENTS}

This study was supported by the project FRG0274-SG-2/2010, a grant from Ministry of Higher Education Malaysia to University Malaysia Sabah.

\section{REFERENCES}

[1] Srinivas, T.N.R., Anil Kumar, P., Sasikala, C., Ramana, C.V. and Imhoff, J.F. (2007) Rhodobacterium from tidal waters, and emended description of the genus Rhodobacter. International Journal of Systematic and Evolutionary Microbiology, 57, 1984-1987. http://dx.doi.org/10.1099/ijs.0.65077-0

[2] Imhoff, J.F. and Hiraishi, A. (2005) Genus I. Rhodobium, In: Garrity, G.M., Brenner, D.J., Krieg, N.R. and Staley, J.T., Eds., Bergey's Manual of Systematic Bacteriology, Vol. 2, Part C: The Alpha-, Beta-, Delta- and EpsilonproTeobacteria, Springer, NewYork, 571-574.

[3] Hiraishi, A., Urata, K. and Satoh, T. (1995) A new genus of marine budding phototrophic bacteria, Rhodobium gen. nov., which includes Rhodobium orientis sp. nov. and Rhodobium marinum comb. nov. International Journal of Systematic Bacteriology, 45, 226-234. http://dx.doi.org/10.1099/00207713-45-2-226

[4] Imhoff, J.F. and Truper, H.G. (1991) A hand book on the biology of bacteria: Ecophysiology, isolation, identification, and application. Springer Verlas, New York.

[5] Azad, S.A., Vikineswary, S., Chong, V.C. and Ramachandran, K.B. (2003) Rhodovulum sulfidophilum in the treatment and utilization of sardine processing wastewater. Letters in Applied Microbiology, 38, 13-18. http://dx.doi.org/10.1046/j.1472-765X.2003.01435.x

[6] Azad, S.A., Chong, V.C. and Vikineswary, S. (2002) Phototrophic bacteria as feed suplliment for rearing Penaeus 
monodon larvae. Journal of the World Aquaculture Society, 33, 991-994.

http://dx.doi.org/10.1111/j.1749-7345.2002.tb00490.x

[7] Tsygankov, A.A., Fedorov, A.S., Talipova, L.V., Laurinavichene, T.V., Miyake, J. and Gogotov, I.N. (1998) Use of immobilized phototrophic microorganisms for wastewater treatment and simultaneous production of hydrogen. Applied Biochemistry and Microbiology, 34, 362-366.

[8] Hirotani, H., Ohigashi, H., Kobayashi, M., Koshinizu, K. and Takashi, E. (1991) Inactivation of T5 phage by cisvaccenic acid and antivirus substances from Rhodopseudomonas capsulate, and by unsaturated fatty acids and related alcohols. FEMS Microbiology Letters, 77, 13-18. http://dx.doi.org/10.1111/j.1574-6968.1991.tb04314.x

[9] Brandl, H., Cross, R.A., Lenz, R.W., Lloyd, R. and Fuller, R.C. (1991) The accumulation of poly (3-hydroxyalkanoates) in Rhodobacter sphaeroides. Archieves of Microbiology, 155, 337-340.

[10] Vatsala, T.M. (1987) Uptake of metal ions by photosynthetic bacterium. Current Science, 56, 1225-1226.

[11] Noparatnaraporn, N. and Nagai, S. (1986) Selection of Rhodobacter sphaeroides $\mathrm{P} 47$ as a useful source of single cell protein. Journal of General and Applied Microbiology, 1, 351-359. http://dx.doi.org/10.2323/jgam.32.351

[12] Tielen, P., Rosenau, F., Wilhelm, S., Jaeger, K.E., Flemming, H.C. and Wingender, J. (2010) Extracellular enzymes affect biofilm formation of mucoid Pseudomonas aeruginosa. Microbiology, 156, 2239-2252. http://dx.doi.org/10.1099/mic.0.037036-0

[13] Oda, K., Tanskull, S., Oyama, H. and Noparatnaraporn, N. (2004) Purification and characterization of alkaline serine proteinase from photosynthetic bacterium, Rubrivivax gelatinosus KDDS1. Bioscience, Biotechnology and Biochemistry, 68, 650-655. http://dx.doi.org/10.1271/bbb.68.650

[14] Prakash, B., Veeregowda, B.M. and Krishnappa, G. (2003) Biofilms: A survival strategy of bacteria. Current Science 85, 1299-1307.

[15] Hanada, S.Y., Kawasw, A., Hiraishi, S., Takaichi, K., Matsuura, K., Shimada, and Nagashima, K.V.P. (1997) Porphyrobacter terpidarius sp. nov., a moderately thermophilic aerobic photosynthetic bacterium isolated from a hot spring. International Journal of Systematic and Evolutionary Microbiology, 47, 408-413.

[16] Chrost, R.J. (1991) Environmental control of the synthesis and activity of aquatic microbial ectoenzymes. In: Chrost, R.J., Ed., Microbial Enzymes in Aquatic Environments. Springer, Berlin, Heidelberg, New York, 29-59.

[17] Prasertsan, P., Choorit, W. and Suwanno, S. (1993) Optimisation for growth of Rhodocyclus gelatinosus in seafood processing effluents. World Journal of Microbiology and Biotechnology, 9, 593-596. http://dx.doi.org/10.1007/BF00386302

[18] Willerding, A.L., de Oliveira, L.A., Moreira, F.W., Germano, M.G. and Chagas, A.F. (2011) Lipase activity among bacteria isolated from amazonian soils. Enzyme Research, 2011, Article ID: 720194. http://dx.doi.org/10.4061/2011/720194
[19] Jain, D., Pancha, I., Mishra, S.K., Shrivastav, A. and Mishra, S. (2011) Purification and characterization of haloalkaline thermoactive, solvent stable and SDS-induced protease from Bacillus sp.: A potential additive for laundry detergents. Bioresource Technology, 115, 228236. http://dx.doi.org/10.1016/j.biortech.2011.10.081

[20] Sawada, H., Parr, R.C. and Roger, P.L. (1977) Photosynthetic bacteria in waste water treatment. Journal of Fermentation Technology, 55, 326-336.

[21] Winkler, U.K. and Stuckman, M. (1978) Glycogen, hyaluronate, and some other polysaccharides greatly enhance the formation of exolipase by serratia marcescens. Journal of Bacteriology, 138, 663-670.

[22] Wang, Y. (2011) Use of probiotics Bacillus coagulans, Rhodopseudomonas palustris and Lactobacillus acidophilus as growth promoters in grass carp (Ctenopharyngodon idella) fingerlings. Aquaculture Nutrition, 17, 37278. http://dx.doi.org/10.1111/j.1365-2095.2010.00771.x

[23] Ainon, H., Tan, C.J. and Vikineswary, S. (2006) Biological characterization of Rhodomicrobium vannielii isolated from a hot spring at Gadek, Malacca, Malaysia. Malaysian Journal of Microbiology, 2, 15-21.

[24] Shivanand, P. and Jayaraman, G. (2009) Production of extracellular protease from halotolerant bacterium, Bacillus aquimaris strain VITP4 isolated from Kumta coast. Process Biochemistry, 44, 1088-1094. http://dx.doi.org/10.1016/j.procbio.2009.05.010

[25] Boominadhan, U., Rajakumar, R., Sivakumaar, P.K.V. and Joe, M.M. (2009) Optimization of protease enzyme production using Bacillus sp. isolated from different wastes. Botany Research International, 2, 83-87.

[26] Bairagi, A., Ghosh, K.S., Sen, S.K. and Ray, A.K. (2002) Enzyme producing bacterial flora isolated from fish digestive tracts. Aquaculture International, 10, 109-121. http://dx.doi.org/10.1023/A:1021355406412

[27] Lensch, M., Herrmann, R.G., and Sokolenko, A. (2001) Identification and characterization of SppA, a novel light inducible chloroplast proteinase complex associated with thylakoid membranes. Journal of Biology and Chemistry, 276, 33645-33651. http://dx.doi.org/10.1074/jbc.M100506200

[28] Singh, S. and Das, S. (2011) Screening, production, optimization and characterization of cyanobacterial polysaccharide. World Journal of Microbiology and Biotechnology, 27, 1971-1980. http://dx.doi.org/10.1007/s11274-011-0657-y

[29] Eroglu, E., Gunduz, U., Yucel, M. and Eroglu, I. (2010) Photosynthetic bacterial growth and productivity under continuous illumination or diurnal cycles with olive mill wastewater as feedstock. International Journal of Hydrogen Energy, 35, 5293-5300. http://dx.doi.org/10.1016/j.ijhydene.2010.03.063

[30] Liqin, S., Changhai, W. and Lei, S. (2008) Effects of light regime on extracellular polysaccharide production by Porphyridium cruentum cultured in flat plate photobioreactors. The 2nd International Conference on Bioinformatics and Biomedical Engineering, ICBBE 2008, Shanghai, 16-18 May 2008, 1488-1491. 